OPEN ACCESS

Edited by:

Renate Helena Maria De Groot, Open University of the Netherlands,

Netherlands

Reviewed by:

Gina Tomé,

University of Lisbon, Portugal

Fotini Venetsanou,

National and Kapodistrian University

of Athens, Greece

*Correspondence:

Xin Luo

xin.luo@snnu.edu.cn

Ji Liu

jiliu@snnu.edu.cn

Specialty section:

This article was submitted to Educational Psychology,

a section of the journal

Frontiers in Psychology

Received: 26 August 2021 Accepted: 17 January 2022

Published: 02 March 2022

Citation:

Luan X, Liu J and Luo X (2022)

Examining the Link Between Physical Activity and Cognitive Function: A

Parallel Mediation Model of Health and Wellbeing Among Adolescents.

Front. Psychol. 13:764842.

doi: 10.3389/fpsyg.2022.764842

\section{Examining the Link Between Physical Activity and Cognitive Function: A Parallel Mediation Model of Health and Wellbeing Among Adolescents}

\author{
Xi Luan, Ji Liu* and Xin Luo* \\ Faculty of Education, Shaanxi Normal University, Xi'an, China
}

Background: Adolescents' engagement in daily physical activity brings multiple benefits, including reduction in obesity, improvement of mental health, and enhancement of cognitive function (CF). While prior studies have examined the link between physical activity and cognitive function, little is known regarding the extent to which this relationship is shaped by health and wellbeing factors. This study examines how subjective wellbeing (SWB) and general health $(\mathrm{GH})$ mediate the relationship between adolescents' physical activity and cognitive function.

Methods: This study estimates a parallel structural equation model using the Program for International Student Assessment 2018 dataset. Specifically, a total of 63,228 15-yearold subjects in nine countries/economies satisfied the study inclusion criteria, including in Bulgaria, Georgia, Hong Kong, Ireland, Mexico, Panama, Serbia, Spain, and United Arab Emirates. Frequency of moderate physical activity (MPA, $\geq 3.0$ Metabolic Equivalent Task) was reported weekly; SWB and GH were assessed using an internationally validated multi-item standardized questionnaire. SWB was measured by students' self-evaluated satisfaction with their health, life, and schooling. GH was measured by students' physical health and mental health status. Cognitive function (CF) was modeled as a latent function consisting of plausible values derived using item response theory on reading, mathematics, and science achievement tests.

Results: Findings indicated that increase in weekly MPA was positively associated with higher levels of SWB $(p<.001), \mathrm{GH}(p<.001)$, and CF $(p<.001)$ among the study subjects. Parallel mediation analyses revealed that more frequent weekly MPA had relatively large direct effects $(p<.001)$ on $C F$, and indirect effects channeling through improvements in SWB and GH were non-trivial $(p<.001)$. Heterogeneity results showed that boosts to CF, associated with MPA, were larger for mathematics and science than for reading $(p<.001)$.

Conclusion: This study used a large-scale international dataset to show that the positive relationship observed between MPA and CF among adolescents was robust, and that SWB and GH were two critical mediators through which physical activity positively bolster CF.

Keywords: moderate physical activity, subjective wellbeing, general health, PISA, structural equation modeling 


\section{INTRODUCTION}

Physical activity is defined as bodily movement that involves skeletal muscles and energy expenditure (Physical Activity Guidelines Advisory Committee, 2018; Sneck et al., 2019). Adolescents are advised by the World Health Organization (WHO) to participate in at least $60 \mathrm{~min}$ of moderate physical activity (MPA) each day in order to stay healthy (World Health Organization, 2010). This volume of physical activity is also recommended by U.S. Department of Health and Human Services (2012), citing its instrumental influence on obesity prevention. However, as academic pressure encroaches on adolescents' life, engagement in MPA has rapidly declined while increase in sedentary behavior has been widely observed (Van Stralen et al., 2014; Hartikainen et al., 2021). This trend, evidenced in recent literature, is likely to pose detrimental risks to adolescents' health, wellbeing, and cognitive function (Corder et al., 2015; Hale et al., 2021).

With regard to adolescents' health and wellbeing, the decreasing level of engagement with MPA negatively influences their musculoskeletal development, diet, sleep, body mass index (BMI), and sensory-motor interaction (Have et al., 2016; Zayed and Jansen, 2018; Barbosa et al., 2020). In addition, studies show that the reduction of MPA involvement can have adverse impacts on adolescents' life satisfaction, self-image, and selfacceptation (Chen et al., 2021). Worryingly, there is a global trend of adolescents' increasing sedentary behavior, which leads to the decline in their MPA involvement (Hale et al., 2021). Accordingly, this is likely to hinder their cognitive, motor, and social development, and is related to lower level of cognitive function (CF) among adolescents due to narrowing chances for neurogenesis, angiogenesis, and enhancement of central nervous system metabolism (Barbosa et al., 2020). As a result, adolescents' executive function may be impacted (Singh et al., 2019). To address these concerns, previous studies have investigated the relationship between MPA involvement and $\mathrm{CF}$, and have found that adolescents' general health $(\mathrm{GH})$ and subjective wellbeing (SWB) benefit from MPA and are both important factors in determining CF (Aadland et al., 2017; Barbosa et al., 2020).

In terms of mechanisms of how MPA influences adolescents' $\mathrm{CF}$, existing evidence has identified three lines of potential channels, including physiological factors, executive function, and learning dispositions. As for the physiological factors, routine MPA is associated with the increase of brain-derived neurotrophic factor, insulin-like growth factor-1 and vascular endothelial growth factor, all of which are strong determinants of developmental growth, maintenance and plasticity of the brain, and are related to CF (Barbosa et al., 2020). Neural growth and enhancement of synaptic transmission can lead to changes in adolescents' prefrontal cortex and improvement of their executive functions including abstract reasoning, planning, and problem solving (Kopp, 2012). In addition, different types of MPA are found to influence CF in different ways. Some MPA can increase physiological arousal, leading to better attention and the release of neurotransmitters, whereas more aerobic MPA improves cardiovascular fitness and ameliorate oxygen saturation and glucose delivery, bringing benefits to neurogenesis and angiogenesis in brain areas that are responsible for CF (Egger et al., 2019; Singh et al., 2019). Besides influencing core executive function, benefits of MPA on adolescents' $\mathrm{CF}$ are also mediated by the cultivation of learning dispositions and learning behaviors during their engagement of MPA which can help them excel in CF tests. The learning dispositions and qualities include organization skills, on-task behaviors and improved school attendance (Álvarez-Bueno et al., 2016).

More importantly, it has been well documented that adolescents' MPA benefits both their physical and mental health (Penedo and Dahn, 2005; Barbosa et al., 2020), thus enhancing the level of their general health (GH) (Carson et al., 2016). On the one hand, in regard to physical health, MPA can ameliorate adolescents' visual-motor coordination and improve their cardiovascular fitness (Cosgrove et al., 2018). MPA can also keep adolescents' physically fit by reducing the chance of obesity and cardio-metabolic disease (Zayed and Jansen, 2018). MPA is also associated with a healthy diet, better sleep and can enhance adolescents CF (Cosgrove et al., 2018). On the other hand, as for the mental health, MPA is related with positive self-image, self-esteem, and self-efficacy. It can effectively reduce depressive symptomatology, psychological stress, and anxiety (Carson et al., 2016; Hale et al., 2021). Adolescents' physical and mental health can in turn benefit cognitive performance and brain development, laying the physiological foundations for CF (Haverkamp et al., 2020). The lack of MPA is, therefore, seen as a major threat for adolescents' GH and CF.

Additionally, subjective wellbeing (SWB) is a critical dimension of adolescents' wellbeing and is a key indicator reflecting quality of life. It is a notion that describes people's life satisfaction, pleasant and unpleasant affect (Hale et al., 2021). Research shows that SWB has close relationship with people's sports involvement. Body image, self-esteem, and personal experience in sports can pose as barriers in sports participation (Martin et al., 2015). Likewise, regular exercise can improve life satisfaction, reduce depressive symptoms and improve mood (Jodra and Domínguez, 2020). By helping people gain social integration, social support and a sense of belonging, MPA is associated with self-acceptation, positive relationship, personal growth, environmental mastery, and purpose of life (Chen et al., 2021).

Despite the above discussions on adolescents' MPA, GH, SWB and CF, there are important gaps needed to fill. Previous research mainly focused on acute physical activity interventions in pre-adolescent children (Haverkamp et al., 2020) and there is a relative lack of research on adolescents and on the effects of regular physical activity (Verburgh et al., 2013; Li et al., 2017; Xue et al., 2019). Furthermore, while most studies examined the effects of MPA on CF, few studies described its effects on CF embodied by the specific fields of language, math, and science (Haapala, 2012). Also, as previous research mainly used interventional approach or conducted metanalysis of the existing study (Egger et al., 2019; Haverkamp et al., 2020), large scale and cross-cultural studies are needed. Finally, little is known about whether GH and SWB, two significant factors benefited from MPA, can mediate the effects of MPA on adolescents' CF. 


\section{MATERIALS AND METHODS}

\section{Constructs and Measures}

This study leveraged the publicly-available Program for International Student Assessment (PISA) 2018 dataset, ${ }^{1}$ which is the flagship project of the Organization for Economic Cooperation and Development (OECD) and sampled 612,004 15 -year-old students in more than 70 economies (Liu and Steiner-Khamsi, 2020). PISA used a multi-stage and multi-strata sampling design, for which schools were sampled with students aged 15-16 at the time of assessment (OECD, 2020). In the first stage, schools were selected using a probability-proportionalto-size sampling approach from a systematic list of eligible schools within participating economies. In the second stage, students were randomly selected from a complete list of eligible 15 -year-old students within each sampled school. In terms of data collection, each sampled student provided detailed background information and completed CF assessment on math, reading, and science competency, in addition to filling a separate youth wellbeing assessment questionnaire which encompassed a series of questions covering life satisfaction, health status, and physical activity.

Program for International Student Assessment contains tests on key cognitive domains and is widely used as an instrument to assess and compare students' school performance and learning dispositions across different countries and regions (Lee and Stankov, 2018). The major cognitive domains in PISA are reading, math and science (Liu, 2019; OECD, 2020), as the knowledge and skills embodied in these domains are widely seen as indicators for the successful participation in contemporary societies and are key to the sustainable growth of modern economy (Heckman and Jacobs, 2009; OECD, 2019; Araújo et al., 2020). Reading domain in PISA tests an individual's capacity to understand, use, evaluate, reflect on and engage with texts to achieve one's goals, develop one's knowledge and potential, and participate in society; math is to examine students' competence to analyze, reason and communicate ideas effectively as they pose, formulate, solve and interpret solutions to mathematical problems; and science domain deals with students' ability to engage with science-related issues, to reason with the ideas of science, as a reflective citizen (OECD, 2020). The results of the cognitive domains in PISA tests attract wide public attention as they offer insights, from a comparative perspective, into the effectiveness of educational policy making and provide large-scale, crosscultural data for research analysis (Araújo et al., 2017).

Apart from the cognitive domains, two key constructs in this study, SWB and GH, are anchored on the PISA 2018 wellbeing survey. In broad strokes, the PISA wellbeing questionnaire was designed to maximize cross-cultural comparability by choosing clear, translatable, quantifiable, and vignette-based Likert-scale items (OECD, 2019). This study leveraged data availability of students' frequency of engagement in MPA, level of SWB and GH, as well as CF assessment in math, reading, and science. Below, a more detailed descriptions

${ }^{1}$ https://www.oecd.org/pisa/data/2018database/ of the predictor variable, mediator variables, and outcome variables are to be reported.

Firstly, MPA [ $\geq 3.0$ Metabolic Equivalent Task (MET)] was the predictor variable in this study. In PISA, MPA is referred as physical activities including but not limited to walking, climbing stairs, riding bicycles, for a total of at least $60 \mathrm{~min}$ per day. Respondents in PISA reported how many days they engaged in these physical activities during the past 7 days.

Secondly, SWB and GH, the two mediator variables in this study, were assessed using an internationally validated multiitem standardized Likert-scale questionnaire in PISA. For SWB, respondents answered ten Likert-scale questions regarding their self-evaluated satisfaction with health, life, and school. The 10 questions are "Your health; the way that you look; what you learn at school; the friends you have; the neighborhood you live in; all the things you have; how you use your time; your relationship with your parents/guardians; your relationship with your teachers; your life at school." For GH, respondents answered nine Likert-scale questions on how often they had some physical or mental health status, including headache, stomach pain, back pain, feeling depressed, irritability or bad temper, feeling nervous, difficulties in getting to sleep, feeling dizzy, and feeling anxious.

Thirdly, CF as the outcome variable was modeled as a latent construct. In PISA's cognitive assessment, emphasis was put on respondents' complex CF, particularly on individuals' capacity to understand, evaluate, formulate, reason, and reflect (OECD, 2018). It was measured by performance in mathematics, reading, and science domains. Leveraging item response theory, ten plausible values were generated for each respondent per subject, and a probability distribution for a student's ability is estimated instead of a direct estimation of a student's ability (OECD, 2009).

\section{Hypotheses}

Based on the discussions of the relationships between MPA, $\mathrm{GH}, \mathrm{SWB}$, and $\mathrm{CF}$, the following hypothesis were made (see Figure 1): adolescents' MPA influences CF (embodied by their performance in PISA math, reading, and science tests), and that $\mathrm{GH}$ and SWB, mediate the effects of MPA on adolescents' $\mathrm{CF}$.

\section{Sample Characteristics}

The inclusion criteria for study subjects were as follows: (1) reported frequency of MPA ( $\geq 3.0 \mathrm{MET})$; (2) reported SWB and $\mathrm{GH}$ using multi-item standardized Likert-scale; and (3) completed cognitive test results for math, reading, and science. A total of 63,228 subjects satisfied the inclusion criteria, and the descriptive statistics for the participating students were presented in Table $\mathbf{1 .}$ These 63,228 students are from nine countries and economies, including Bulgaria, Georgia, Hong Kong, Ireland, Mexico, Panama, Serbia, Spain, and United Arab Emirates. Among these students, $32,562(51.5 \%)$ were female. The participants' age ranged from 15.812 to $15.816(M=21.26, \mathrm{SD}=.29)$. On average, these students in the sample reported 3.168 times of MPA. The average scores of their test results on math, reading, and science were 474.004, 471.488 , and 470.640 , respectively. 


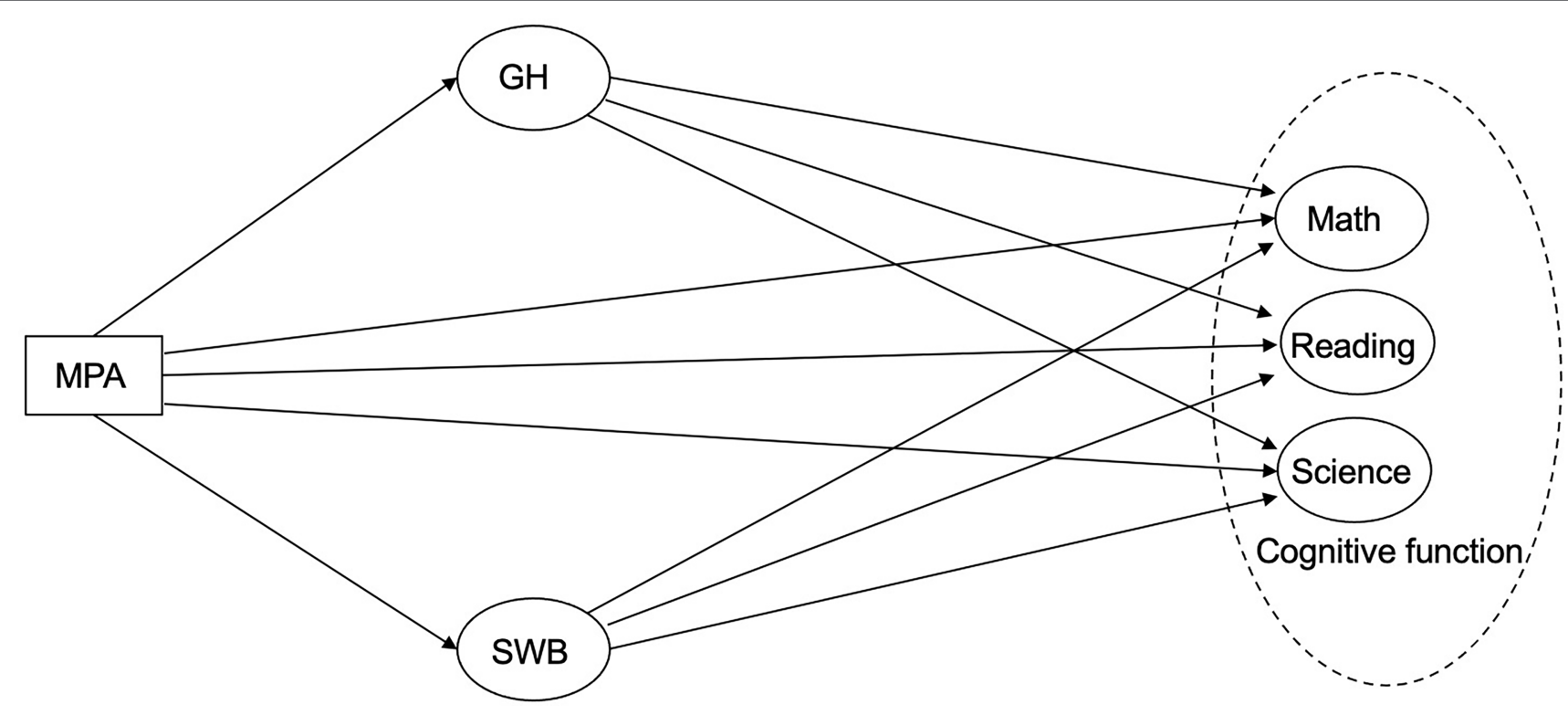

FIGURE 1 | Conceptual diagram.

TABLE 1 | Demographic information of participants and descriptions of predictor and outcome variables $(N=63,228)$.

\begin{tabular}{lrrrr}
\hline & & & \multicolumn{2}{c}{$\mathbf{9 5 \%}$ Cl } \\
\cline { 4 - 5 } Variable & Mean & SD & Lower & Upper \\
\cline { 3 - 5 } & & & - & - \\
\hline Female & .515 & - & 15.812 & 15.816 \\
Age & 15.814 & .290 & 3.149 & 3.186 \\
MPA & 3.168 & .010 & 375.137 & 572.871 \\
Math & 474.004 & 98.867 & & 572.932 \\
(10 plausible values) & & & & \\
Reading & 471.488 & 101.444 & 370.044 & 567.666 \\
(10 plausible values) & & & & \\
Science & 470.640 & 97.026 & 373.614 & \\
(10 plausible values) & & & & \\
\hline
\end{tabular}

\section{Statistical Analysis}

The study utilized structural equation modeling (SEM) to examine the relationship between MPA and CF, and fitted a parallel mediation model to evaluate the extent to which SWB and GH mediated their relationship. In recent decades, SEM has grown in popularity in scientific inquiry, especially among new applications in educational psychology research (Karimi and Meyer, 2014). Methodologically speaking, SEM allows the researcher to statistically examine the extent to which proposed hypotheses are supported by empirical data to reflect theoretical predictions (Kline, 2015).

This present study utilized partial least squares SEM model (PLS-SEM). All analyses were performed using STATA version 15.0 (Stata, StataCorp LLC, College Station, TX, United States) software. Several goodness of fit indices was tested to evaluate how well the structural models fitted the data. The comparative fit index was computed to be .912 , while Tucker-Lewis index was computed to be .905 . Both were higher than .9 , suggesting that the data displayed a reasonable fit for the model (Bentler, 1990). The value of Root Mean Square Error of Approximation was .104, which was marginally above the goodness-of-fit threshold of .10 (McDonald and Marsh, 1990).

\section{RESULTS}

\section{Measurement Model}

While PISA 2018 has already categorized survey items by broad construct groupings, we report psychometric properties of presumed scales and assess measurement model fit (Matsunga, 2010). Tables 2 and $\mathbf{3}$ presented results from the measurement models, with information on factor loadings. Importantly, all item loading values were above .60, showing good explanation of each factor, which indicated good internal consistency and construct validity (Hair et al., 2010, 2016). The internal consistency of both variables was assessed using Cronbach's $\alpha$, which was .892 for SWB and .880 for GH. In Table 4, we reported correlation coefficients between constructs, and found that all construct pairs exhibited significant and positive associations.

\section{Structural Equation Modeling}

The estimation of standardized direct effects was reported in Table 5. MPA had significant positive effects on both GH and SWB. The path coefficient from MPA to GH was significant $(.189, p<.001)$, and so was the path coefficient from MPA to SWB $(.183, p<.001)$. That is, both GH and SWB were influenced by students' MPA.

CF was assessed using three cognitive test domains in PISA. MPA was positively related to students' scores on math. The 
TABLE 2 | Reliability and convergent validity of subjective wellbeing $(N=63,228)$.

\begin{tabular}{ll}
\hline Items & Factor loadings \\
\hline 1. Your health & .691 \\
2. The way that you look & .694 \\
3. What you learn at school & .691 \\
4. The friends you have & .699 \\
5. The neighborhood you live in & .699 \\
6. All the things you have & .756 \\
7. How you use your time & .711 \\
8. Your relationship with your parents/guardians & .735 \\
9. Your relationship with your teachers & .721 \\
10. Your life at school & .751
\end{tabular}

TABLE 3 | Reliability and construction validity of general health $(N=63,228)$.

\begin{tabular}{lc}
\hline Items & Factor loadings \\
\hline 1. Headache & .688 \\
2. Stomach pain & .673 \\
3. Back pain & .627 \\
4. Feeling depressed & .757 \\
5. Irritability or bad temper & .753 \\
6. Feeling nervous & .749 \\
7. Difficulties in getting to sleep & .699 \\
8. Feeling dizzy & .745 \\
9. Feeling anxious & .754
\end{tabular}

path coefficient from MPA to math was .036 $(p<.001)$. This result demonstrated that each additional MPA per week was associated with .036 more standardized scores on math. Students' performance on reading was also positively influenced by their MPA $(.027, p<.001)$. Moreover, positive effect was in correlation with MPA on the subject of science. The path coefficient from MPA to science was $.034(p<.001)$, indicating that each additional MPA active day was related to .034 higher standard deviations on $\mathrm{CF}$ in math.

$\mathrm{GH}$ showed direct effects on CF. According to the model, the path coefficient from $\mathrm{GH}$ to math was significant (.013, $p<.001)$. Meanwhile, the path coefficient from $\mathrm{GH}$ to reading was also positive and significant $(.006, p<.000)$. It can be also observed that $\mathrm{GH}$ had positive and significant effects on students' achievements on science tests in PISA $(.011, p<.001)$. The results suggested that students who reported higher level of GH were likely to achieve more on math, reading, and science.

Subjective wellbeing had a positive and significant effect on math $(.004, p<.001)$. From SWB to reading, there was also a direct path with a significant path coefficient (.008, $p<.001)$. Moreover, it can be also observed that SWB (.005, $p<.001)$ had a positive and significant effect on students' science tests in PISA. Therefore, students' higher level of SWB was associated with better CF.

According to the model, a consistent pattern was observed among math, reading, and science. Students' CF on math, reading, and science was all found to be related to MPA, while there were differences on the path coefficients. The results of the model suggested that each additional MPA per week indicated additional .036 standard scores on math, .034 standardized scores on science, and .027 standardized scores on reading. Furthermore, GH was demonstrated to have positive and significant effects on all the subjects. Similarly, the positive effect of GH was comparatively higher on math (.013) and science (.011), and lower on reading (.006). In the meantime, all the three subjects were directly associated with the variable of SWB. Whereas, students with higher level of SWB tended to score higher on reading $(.008, p=.000)$, math $(.004, p=.000)$, and science $(.005, p=.000)$.

The analysis above addressed the direct effect of MPA on $\mathrm{CF}$, the influence of the mediators, GH and SWB, is shown in Figure 2 and Table 6 and is to be reported below. Firstly, as for the effects of MPA on math, this study tested the indirect effects via the influence of SWB and GH respectively. Both SWB (standardized indirect effect $=.001$ ) and GH (standardized indirect effect $=.003$ ) were simultaneously. Both indirect path coefficients tested in our models were positive and significant. Combined with the direct effect (direct effect $=.036$ ), the total effect of MPA on math was .039 .

Secondly, concerning the effects of MPA on reading, MPA had indirect effects on reading through $\mathrm{GH}$ (standardized indirect effect $=.001$ ) and through SWB (standardized indirect effect $=.002$ ) respectively. Both these indirect path coefficients in models were positive and significant. Thus, with the direct effect (.027), the total effect of MPA on reading was computed as .029 .

Lastly, as for the effects of MPA on science, both GH and SWB were found to be mediators (standardized indirect effects are .002 and .001 respectively). The total indirect effect was .003. Adding to the direct effect of MPA on science (direct effect $=.034$ ), the total effects of MPA on science were .037 .

\section{DISCUSSIONS AND CONCLUSIONS}

This study investigated the effects of MPA on student's CF. Existing research have demonstrated the significance of MPA on CF. Yet there is a lack of study focusing on the effects of MPA among adolescents and the mediating roles of $\mathrm{GH}$ and SWB. To fill the gap, this study explored the direct effects of MPA on adolescents' CF based on large-scale, crosscultural data and examined the mediating channels of $\mathrm{GH}$ and SWB.

Our findings demonstrated that MPA had both direct and indirect positive effects on students' CF. The path coefficient from MPA to GH was $.189(p<.001)$, while the path coefficient from MPA to SWB was .183 $(p<.001)$. MPA was found to have positive direct effects on math (path coefficient $=.036$, $p<.001)$, reading $(.027, p<.001)$, and science $(.034, p<.001)$. $\mathrm{GH}$ and SWB were found to play significant mediating roles. Through the mediation of GH, MPA had an indirect influence on math $(.003, p=.000)$, reading $(.001, p=.000)$, and science $(.002, p=.000)$. Meanwhile, SWB mediated the effects of MPA on math $(.001, p=.000)$, reading $(.002, p=.000)$, and science $(.001, p=.000)$. To put this number in broader context, OECD (2016) reported .25 to .30 standard deviations as the 
TABLE 4 | Correlation matrix of SEM input measures $(N=63,228)$.

\begin{tabular}{|c|c|c|c|c|c|c|}
\hline & 1 & 2 & 3 & 4 & 5 & 6 \\
\hline 1. MPA & - & & & & & \\
\hline 2. SWB & $.072 * * *$ & - & & & & \\
\hline 3. $\mathrm{GH}$ & $.051 * * *$ & $.351 * * *$ & - & & & \\
\hline 4. Math & $.093 * * *$ & $.114 * * *$ & $.152 * * *$ & - & & \\
\hline 5. Reading & $.071 * * *$ & $.116 * * *$ & $.097 * * *$ & $.829 * * *$ & - & \\
\hline 6. Science & $.088 * * *$ & $.114 * * *$ & $.135 * * *$ & $.845 * * *$ & $.881 * * *$ & - \\
\hline
\end{tabular}

$* * * p<.001$

TABLE 5 | Standardized direct effects of the SEM model $(N=63,228)$.

\begin{tabular}{|c|c|c|c|c|c|}
\hline \multirow{2}{*}{ Pathways } & \multirow{2}{*}{ Std. coefficient } & \multirow{2}{*}{ SE } & \multirow{2}{*}{ Value of $p$} & \multicolumn{2}{|c|}{$95 \% \mathrm{Cl}$} \\
\hline & & & & Lower & Upper \\
\hline $\mathrm{MPA} \rightarrow \mathrm{GH}$ & .189 & .014 & .000 & .163 & .216 \\
\hline $\mathrm{MPA} \rightarrow \mathrm{SWB}$ & .183 & .009 & .000 & .165 & .202 \\
\hline MPA $\rightarrow$ Math & .036 & .001 & .000 & .034 & .039 \\
\hline MPA $\rightarrow$ Reading & .027 & .001 & .000 & .024 & .030 \\
\hline MPA $\rightarrow$ Science & .034 & .001 & .000 & .031 & .037 \\
\hline $\mathrm{GH} \rightarrow$ Math & .013 & .000 & .000 & .012 & .014 \\
\hline $\mathrm{GH} \rightarrow$ Reading & .006 & .000 & .000 & .005 & .007 \\
\hline $\mathrm{GH} \rightarrow$ Science & .011 & .000 & .000 & .010 & .012 \\
\hline SWB $\rightarrow$ Math & .004 & .001 & .000 & .003 & .005 \\
\hline SWB $\rightarrow$ Reading & .008 & .001 & .000 & .007 & .009 \\
\hline SWB $\rightarrow$ Science & .005 & .001 & .000 & .004 & .007 \\
\hline
\end{tabular}

$C F I=.912 ; T L I=.905 ; R M S E A=.104 ; \chi^{2}(487)=37,8631.66$.

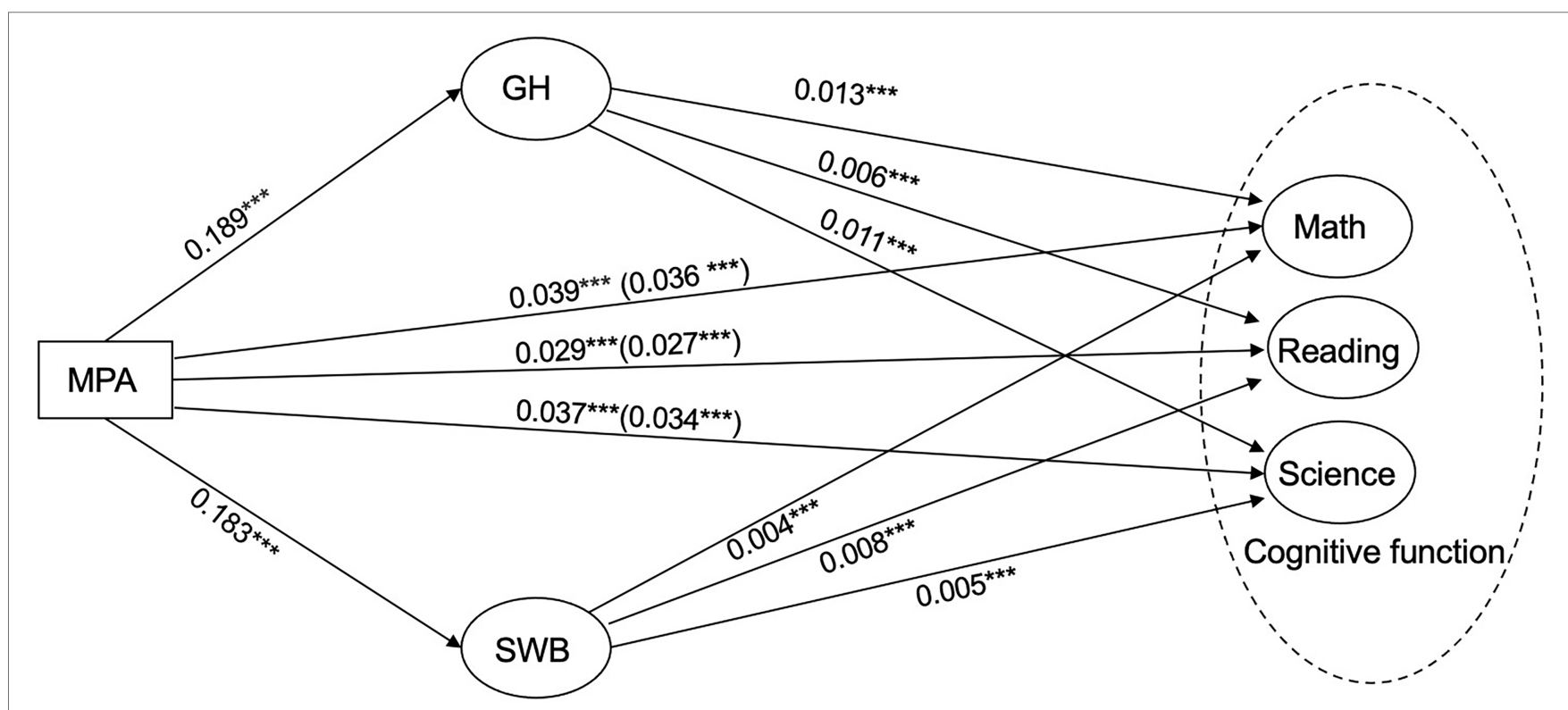

FIGURE 2 | The full parallel mediation model. ${ }^{\star * \star} \mathrm{p}<0.001$, parenthetical=after adding mediating variable coefficients.

amount of expected learning gains per year among middleto-high income countries, while Evans and Yuan (2019) estimated learning gains per year between .15 and .21 standard deviations among low-to-middle income countries. Based on these prior estimates, conservative calculations indicated that our findings of .036 standard deviations increase in student 
TABLE 6 | Standardized indirect effects and 95\% confidence intervals for the model $(N=63,228)$.

\begin{tabular}{|c|c|c|c|c|c|}
\hline \multirow{2}{*}{ Pathways } & \multirow{2}{*}{ Std. coefficient } & \multirow{2}{*}{ SE } & \multirow{2}{*}{ Value of $p$} & \multicolumn{2}{|c|}{$95 \% \mathrm{Cl}$} \\
\hline & & & & Lower & Upper \\
\hline $\mathrm{MPA} \rightarrow \mathrm{GH} \rightarrow$ Math & .003 & .000 & .000 & .002 & .003 \\
\hline $\mathrm{MPA} \rightarrow \mathrm{SWB} \rightarrow$ Math & .001 & .000 & .000 & .001 & .001 \\
\hline MPA $\rightarrow$ Math & .003 & .000 & .000 & .003 & .004 \\
\hline $\mathrm{MPA} \rightarrow \mathrm{GH} \rightarrow$ Reading & .001 & .000 & .000 & .001 & .001 \\
\hline $\mathrm{MPA} \rightarrow$ SWB $\rightarrow$ Reading & .002 & .000 & .000 & .001 & .002 \\
\hline MPA $\rightarrow$ Reading & .003 & .000 & .000 & .002 & .003 \\
\hline $\mathrm{MPA} \rightarrow \mathrm{GH} \rightarrow$ Science & .002 & .000 & .000 & .002 & .002 \\
\hline $\mathrm{MPA} \rightarrow$ SWB $\rightarrow$ Science & .001 & .000 & .000 & .001 & .001 \\
\hline MPA $\rightarrow$ Science & .003 & .000 & .000 & .003 & .004 \\
\hline
\end{tabular}

learning outcomes approximately corresponded to between 1.4 and 1.8 additional months of learning in a typical 9-month school year.

The fulfillment of the hypothesis and contributions of this study are discussed as follows. First, since PISA 2018 dataset included information on students' MPA and cognitive test results for math, reading, and science, this study managed to utilize SEM to evaluate the relationship between MPA and CF. Our analysis indicated that adolescents' MPA had positive and significant direct effects on CF, which was consistent with previous research highlighting the role of physical activities in improving academic performance (Bedard et al., 2019; Barbosa et al., 2020).

Second, this study conceptualized students' CF as their math, reading, and science achievements in PISA 2018. Through our analysis, it turned out that the effects of MPA were positive and significant on all the three subjects. In contrast, previous studies have reported inconsistent findings. For instance, Spruit et al. (2016) found positive effects of physical activities on science, including math, but not on language. While ÁlvarezBueno et al. (2016) reported positive effects on both language and math. Using a large and cross-cultural sample, this study reexamine inconclusive findings in existing literature.

This study also examined two potential mediation factors, adolescents' $\mathrm{GH}$ and SWB, were found to mediate the effects of MPA on CF. By utilizing SEM, this study evaluated the extent to which SWB and GH mediated their relationship. These results have deepened to the understandings on the indirect effects of MPA on adolescents' academic performance discussed in previous research (Sneck et al., 2019).

This study has the following implications: on the methodological level, it advanced the current discussions on MPA and CF. It used large and cross-cultural data, to study the relationship between MPA and adolescents' CF and how $\mathrm{GH}$ and SWB mediate it. On the policy level, it reminds policymakers that it is beneficial to encourage MPA in schools;

\section{REFERENCES}

Aadland, K. N., Moe, V. F., Aadland, E., Anderssen, S. A., Resaland, G. K., and Ommundsen, Y. (2017). Relationships between physical activity, sedentary time, aerobic fitness, motor skills and executive function and academic also, in order to improve adolescents' CF, and school performance, educational stakeholders, including governments, schools, community, and parents, should work together to improve adolescents' GH and SWB are important mechanism factors to consider.

This study mainly depended on the large, statistical data. Future research can go deep into the mechanism to explore the physiological foundations of the model. Pedagogical research is also needed to study how curriculum and educational reforms may benefit from these findings. The reasons behind differences among the subjects were not fully explored in the current study, which also requires further investigation.

\section{DATA AVAILABILITY STATEMENT}

Publicly available datasets were analyzed in this study. This data can be found online at: https://www.oecd.org/pisa/ data/2018database/; OECD:PISA 2018 Database.

\section{AUTHOR CONTRIBUTIONS}

XLuan organized the team, managed the research project, and participated in the analysis of data and the preparation of manuscript. JL conceived and designed the study. XLuo did the literature review, participated in the analysis of data, and managed the corresponding issues. All authors contributed to the article and approved the submitted version.

\section{FUNDING}

This work was supported by Researchers' Start-up Fund of Shaanxi Normal University (funding No. 1301032077). performance in children. Ment. Health Phys. Act. 12, 10-18. doi: 10.1016/j. mhpa.2017.01.001

Álvarez-Bueno, C., Pesce, C., Cavero-Redondo, I., Sánchez-López, M., Pardo-Guijarro, M. J., and Martínez-Vizcaíno, V. (2016). Association of physical activity with cognition, metacognition and academic performance 
in children and adolescents: a protocol for systematic review and metaanalysis. BMJ Open 6:e011065. doi: 10.1136/bmjopen-2016-011065

Araújo, L., Costa, P., and Crato, N. (2020). "Assessment background: what PISA measures and how," in Improving a Country's Education PISA 2018 Results in 10 Countries. ed. N. Crato (Cham: Springer), 249-263.

Araújo, L., Saltelli, A., and Schnepf, S. V. (2017). Do PISA data justify PISAbased education policy? Int. J. Comp. Educ. Dev. 19, 20-34. doi: 10.1108/ IJCED-12-2016-0023

Barbosa, A., Whiting, S., Simmonds, P., Scotini Moreno, R., Mendes, R., and Breda, J. (2020). Physical activity and academic achievement: an umbrella review. Int. J. Environ. Res. Public Health 17:5972. doi: 10.3390/ ijerph17165972

Bedard, C., St John, L., Bremer, E., Graham, J. D., and Cairney, J. (2019). A systematic review and meta-analysis on the effects of physically active classrooms on educational and enjoyment outcomes in school age children. PLoS One 14:e0218633. doi: 10.1371/journal. pone.0218633

Bentler, P. M. (1990). Comparative fit indexes in structural models. Psychol. Bull. 107, 238-246. doi: 10.1037/0033-2909.107.2.238. PMID: 2320703

Carson, V., Hunter, S., Kuzik, N., Gray, C. E., Poitras, V. J., Chaput, J. P., et al. (2016). Systematic review of sedentary behaviour and health indicators in school-aged children and youth: an update. Appl. Physiol. Nutr. Metab. 41, S240-S265. doi: 10.1139/apnm-2015-0630

Chen, S., Calderón-Larrañaga, A., Saadeh, M., Dohrn, I. M., and Welmer, A. K. (2021). Correlations of subjective and social well-being with sedentary behavior and physical activity in older adults - a population-based study. J. Gerontol. A Biol. Sci. Med. Sci. 76, 1789-1795. doi: 10.1093/gerona/ glab065

Corder, K., Atkin, A. J., Bamber, D. J., Brage, S., Dunn, V. J., Ekelund, U., et al. (2015). Revising on the run or studying on the sofa: prospective associations between physical activity, sedentary behaviour, and exam results in British adolescents. Int. J. Behav. Nutr. Phys. Act. 12:106. doi: 10.1186/ s12966-015-0269-2

Cosgrove, J. M., Chen, Y. T., and Castelli, D. M. (2018). Physical fitness, grit, school attendance, and academic performance among adolescents. Biomed. Res. Int. 2018:9801258. doi: 10.1155/2018/9801258

Egger, F., Benzing, V., Conzelmann, A., and Schmidt, M. (2019). Boost your brain, while having a break! The effects of long-term cognitively engaging physical activity breaks on children's executive functions and academic achievement. PLoS One 14:e0212482. doi: 10.1371/journal.pone.0212482

Evans, D., and Yuan, F. (2019). "Equivalent years of schooling: a metric to communicate learning gains in concrete terms". World Bank Policy Research Working Paper 8752; February 19, 2019.

Haapala, E. A. (2012). Physical Activity, Academic Performance and Cognitionin Children and Adolescents. A Systematic Review. Baltic Journal of Health and Physical Activity 4, 147-155. doi: 10.2478/v10131-012-0007-y

Hair, J., Black, W., Babin, B., and Anderson, R. (2010). Multivariate Data Analysis. Saddle River, NJ: Prentice-Hall.

Hair, J., Hult, G., Ringle, C., and Sarstedt, M. (2016). A Primer on Partial Least Squares Structural Equation Modeling (PLS-SEM). Thousand Oaks: Sage.

Hale, G. E., Colquhoun, L., Lancastle, D., Lewis, N., and Tyson, P. J. (2021). Review: physical activity interventions for the mental health and well-being of adolescents - a systematic review. Child Adolesc Ment Health. 26, 357-368. doi: $10.1111 /$ camh. 12485

Hartikainen, J., Haapala, E. A., Poikkeus, A. M., Lapinkero, E., Pesola, A. J., Rantalainen, T., et al. (2021). Comparison of classroom-based sedentary time and physical activity in conventional classrooms and open learning spaces among elementary school students. Front. Sports Act. Living 3:626282. doi: $10.3389 /$ fspor.2021.626282

Have, M., Nielsen, J. H., Gejl, A. K., Thomsen Ernst, M., Fredens, K., Støckel, J. T., et al. (2016). Rationale and design of a randomized controlled trial examining the effect of classroom-based physical activity on math achievement. BMC Public Health 16:304. doi: 10.1186/s12889-016-2971-7

Haverkamp, B. F., Wiersma, R., Vertessen, K., van Ewijk, H., Oosterlaan, J., and Hartman, E. (2020). Effects of physical activity interventions on cognitive outcomes and academic performance in adolescents and young adults: a meta-analysis. J. Sports Sci. 38, 2637-2660. doi: 10.1080/02640414.2020.1794763

Heckman, J., and Jacobs, B. (2009). Policies to create and destroy human capital in Europe. US National Bureau of Economic Research. Available at: https://capitalism.columbia.edu/files/ccs/workingpage/2015/ccswp7_ heckmanjacobs.pdf (Accessed February 25, 2010).

Jodra, P. Y., and Domínguez, R. (2020). Effects of physical activity on the perceived general health of teachers. Revista Internacional de Medicina $y$ Ciencias de la Actividad Física y el Deporte. 20, 155-166. doi: 10.15366/ rimcafd2020.77.010

Karimi, L., and Meyer, D. (2014). Structural equation modeling in psychology: the history, development and current challenges. Int. J. Psychol. Stud. 6, 123-133. doi: 10.5539/ijps.v6n4p123

Kline, R. (2015). Principles and Practice of Structural Equation Modeling. New York, NY: Guilford Publications.

Kopp, B. (2012). A simple hypothesis of executive function. Front. Hum. Neurosci. 6:159. doi: $10.3389 /$ fnhum.2012.00159

Lee, J., and Stankov, L. (2018). Non-cognitive predictors of academic achievement: evidence from TIMSS and PISA. Learn. Individ. Differ. 65, 50-64. doi: 10.1016/j.lindif.2018.05.009

Li, J. W., O'Connor, H., O'Dwyer, N., and Orr, R. (2017). The effect of acute and chronic exercise on cognitive function and academic performance in adolescents: a systematic review. J. Sci. Med. Sport 20, 841-848. doi: 10.1016/j. jsams.2016.11.025

Liu, J. (2019). Government, media, and citizens: understanding engagement with PISA in China (2009-2015). Oxf. Rev. Educ. 45, 315-332. doi $10.1080 / 03054985.2018 .1518832$

Liu, J., and Steiner-Khamsi, G. (2020). Human capital index and the hidden penalty for non-participation in ILSAs. Int. J. Educ. Dev. 73:102149. doi: 10.1016/j.ijedudev.2019.102149

Martin, A., Fitzsimons, C., Jepson, R., Saunders, D. H., vander Ploeg, H. P., Teixeira, P. J., et al. (2015). EuroFIT consortium. Interventions with potential to reduce sedentary. Br. J Sports. Med. 49, 1056-1063. doi: 10.1136/ bjsports-2014-094524

Matsunga, M. (2010). How to factor-analyze your data right: do's and don'ts and how to's. Int. J. Psychol. Res. 3, 97-110. doi: 10.21500/20112084.854

McDonald, R. P., and Marsh, H. W. (1990). Choosing a multivariate model: noncentrality and goodness of fit. Psychol. Bull. 107, 247-255. doi: 10.1037/0033-2909.107.2.247

OECD (2009). PISA Data Analysis Manual: SPSS. 2nd Edn. Paris: OECD Publishing. OECD (2016), Education at a Glance 2016: OECD Indicators. Paris: OECD Publishing.

OECD (2018). PISA 2018 Student Questionnaire; OECD: Paris, France. Available at: https://www.oecd.org/pisa/data/2018database/CY7_201710_QST_MS_STQ_ UH_NoNotes.pdf (Accessed August 1, 2021).

OECD (2019), PISA 2018 Assessment and Analytical Framework, Paris: OECD Publishing.

OECD (2020). PISA 2018 Technical Report; OECD: Paris, France. Available at: https://www.oecd.org/pisa/data/pisa2018technicalreport/ (Accessed August 1, 2021).

Penedo, F. J., and Dahn, J. R. (2005). Exercise and well-being: a review of mental and physical health benefits associated with physical activity. Curr Opin. Psychiatry 18, 189-193. doi: 10.1097/00001504-200503000-00013

Physical Activity Guidelines Advisory Committee [PAGAC] (2018). Physical Activity Guidelines Advisory Committee Scientific Report. Washington, DC: U.S. Department of Health and Human Services.

Singh, A. S., Saliasi, E., van den Berg, V., Uijtdewilligen, L., de Groot, R. H. M., Jolles, J., et al. (2019). Effects of physical activity interventions on cognitive and academic performance in children and adolescents: a novel combination of a systematic review and recommendations from an expert panel. Br. J. Sports Med. 53, 640-647. doi: 10.1136/bjsports-2017-098136

Sneck, S., Viholainen, H., Syväoja, H., Kankaapää, A., Hakonen, H., Poikkeus, A. M., et al. (2019). Effects of school-based physical activity on mathematics performance in children: a systematic review. Int. J. Behav. Nutr. Phys. Act. 16:109. doi: 10.1186/s12966-019-0866-6

Spruit, A., Assink, M., van Vugt, E., van der Put, C., and Stams, G. J. (2016) The effects of physical activity interventions on psychosocial outcomes in adolescents: a meta-analytic review. Clin. Psychol. Rev. 45, 56-71. doi: 10.1016/j.cpr.2016.03.006

U.S. Department of Health and Human Services [USDHHS] (2012). "National Health and nutrition examination survey," in Key Statistics From NHANES (Washington, DC: Centers for Disease Control and Prevention, US Department of Health and Human Services). 
Van Stralen, M. M., Yildırım, M., Wulp, A., te Velde, S. J., Verloigne, M., Doessegger, A., et al. (2014). Measured sedentary time and physical activity during the school day of European 10- to 12-year-old children: the ENERGY project. J. Sci. Med. Sport 17, 201-206. doi: 10.1016/j.jsams.2013.04.019

Verburgh, L., Knigs, M., Scherder, E. J., and Oosterlaan, J. (2013). Physical exercise and executive functions in preadolescent children, adolescents and young adults: a meta-analysis. Br. J. Sports Med. 48, 973-979. doi: 10.1136/ bjsports-2012-091441

World Health Organization [WHO] (2010). Global Recommendations on Physical Activity for Health. Geneva, Switzerland: World Health Organization.

Xue, Y., Yang, Y., and Huang, T. (2019). Effects of chronic exercise interventions on. Executive function among children and adolescents: a systematic review with meta-analysis. Br. J. Sports Med. 53, 1397-1404. doi: 10.1136/ bjsports-2018-099825

Zayed, K., and Jansen, P. (2018). Gender differences and the relationship of motor, cognitive and academic achievement in Omani primary school-aged children. Front. Psychol. 9:2477. doi: 10.3389/fpsyg.2018.02477
Conflict of Interest: The authors declare that the research was conducted in the absence of any commercial or financial relationships that could be construed as a potential conflict of interest.

Publisher's Note: All claims expressed in this article are solely those of the authors and do not necessarily represent those of their affiliated organizations, or those of the publisher, the editors and the reviewers. Any product that may be evaluated in this article, or claim that may be made by its manufacturer, is not guaranteed or endorsed by the publisher.

Copyright (C) 2022 Luan, Liu and Luo. This is an open-access article distributed under the terms of the Creative Commons Attribution License (CC BY). The use, distribution or reproduction in other forums is permitted, provided the original author(s) and the copyright owner(s) are credited and that the original publication in this journal is cited, in accordance with accepted academic practice. No use, distribution or reproduction is permitted which does not comply with these terms. 